\title{
TRABALHO EM TRANSFORMAÇÃO: DO COWORKING AO HOME OFFICE AS NOVAS FORMAS DE ATUAÇÃO FRENTE À PANDEMIA
}

Márcia Regina Almeida - almeidamarcia10@gmail.com ${ }^{1}$ Lurdes Marlene Seide Froemming - Lurdesfr@hotmail.com Simone Beatriz Nunes Ceretta - simone.ceretta@iffarroupilha.edu.br ${ }^{2}$

Resumo - O presente artigo, primeiramente se propôs a entender uma nova forma de trabalho em ambientes de varejo. O ambiente pesquisado denomina-se Coffe Shop, utilizado como ponto de lazer, encontros e também para reuniões de trabalho. Os atributos destacados pelos entrevistados configuraram o espaço como um coworking, com estrutura tecnológica e de viés colaborativo para a configuração de novas ideias. As transformações abruptas que vieram com a pandemia, a partir de março de 2020, alteraram as formas de trabalho para muitos profissionais, não se sabe se serão momentâneas ou não, mas houve a possibilidade de ampliação da pesquisa frente ao contexto vigente com a COVID-19. Do coworking ao home office, muitas pessoas tiveram que assumir novas formas de realizar as suas atividades, dessa forma, a pesquisa também ampliou o seu escopo e apontou alguns percalços e benefícios do tele-trabalho, como a possibilidade de realizar o distanciamento social, mas também a dificuldade de conciliar a rotina doméstica com as atividades da empresa.

Palavras-chave: coworking; tele-trabalho; varejo; COVID-19.

\section{WORKING IN TRANSFORMATION: FROM COWORKING TO HOME OFFICE THE NEW WAYS OF OPERATION IN FRONT OF THE PANDEMIC}

\begin{abstract}
The present article, first proposed to understand a new way of working in retail environments. The researched environment is called Coffe Shop, used as a leisure point, meetings and also for business meetings. The attributes highlighted by the interviewees configured the space as coworking, with a technological structure and a collaborative bias for the configuration of new ideas. The abrupt transformations that came with the pandemic, starting in March 2020, changed the ways of working for many professionals, it is not known whether they will be momentary or not, but there was the possibility of expanding the research in the current context with COVID- 19. From coworking to home office, many people had to take new ways to carry out their activities, so the research also broadened its scope and pointed out some problems and benefits of tele-work, such as the possibility of achieving social distancing, but also the difficulty of reconciling the domestic routine with the company's activities.
\end{abstract}

Keywords: coworking; tele-work; retail; COVID-19.

Data de Submissão: 21/06/2020

Data de Aceitação: 01/08/2020 


\section{Introdução}

Este artigo trata do coworking como uma perspectiva de novas configurações do trabalho. Estava pronto para editar, quando surgem mudanças radicais, delineando o mundo de incertezas em que vivemos, desestabilizando nossos conceitos e certezas. É a pandemia do coronavirus, sintonizando o caos em nossos modos de fazer e de viver. Decidiu-se manter o artigo com sua proposta e tema já delineados, para no final abordar interrelações, consequências e caminhos possíveis.

O varejo, considerado um dos setores que mais demanda por inovações devido ao relacionamento direto com os consumidores, carece de novos formatos de loja, que permitam vivências e formas de trabalho diferenciadas. Nesse cenário, o estudo objetiva apresentar um modelo que denominamos de "espaço varejista multifuncional para um consumidor multifuncional", o qual se apresenta em um contexto de coworking, mais especificamente, Coffee Shop.

As exigências e também as oportunidades do momento propiciam novas configurações de muitas ideias, ações, processos já existentes, transformando-se em atos de criatividade. Caracterizado como um setor extremamente dinâmico, de mudanças constantes, o varejo apresenta tendências que devem ser consideradas pelo gestor contemporâneo no planejamento de suas estratégias competitivas, neste momento de pandemia, ainda de um modo mais crucial.

De acordo com Parente (2000), as tendências ajudam a prever o futuro e podem ser definidas como uma direção ou sequência de eventos que tem algum momento ou durabilidade e, em consequência, muitas oportunidades de mercado podem ser detectadas por meio da análise das tendências socioculturais que acabam influenciando o comportamento do consumidor. Assim, uma nova forma de trabalho que surge hodiernamente e que se denomina coworking, vem alavancando espaço nas lojas varejistas.

O fenômeno coworking surge de novos formatos das relações de trabalho, propiciadas com o desenvolvimento de avanços tecnológicos que permitem o fenômeno da execução do trabalho a distância. Não se trata apenas de uma partilha de um espaço físico, mas também possibilita o desenvolvimento e o estabelecimento de uma comunidade de pessoas, de pensamento similar que compartilham os mesmos valores, criando sinergias. É o reflexo dos novos valores do mundo contemporâneo (HUWART; DICHTER; VANRIE, 2012). O ser humano sendo um ser social, em algumas circunstâncias precisa da interação social, intermediado pela comunicação oral. Qual espaço varejista poderia então, propiciar esses encontros?

Alguns espaços e necessidades de compartilhamento resultam em construções informais de um assemelhado a coworking. Novos espaços e formatos de lojas de varejo oportunizam essa formação.

Correlacionando esses preceitos, apresenta-se um modelo que denominamos de "espaço varejista multifuncional para um consumidor multifuncional", que surge no varejo e no caso, o apresentamos em um contexto de coworking. Busca-se descrever o que já é ofertado para que potenciais consumidores se sintam interessados por esses locais e lhes atribuam novas identidades. 
O estudo realizado na empresa Literatus Xok's, é de caráter qualitativo e exploratório, configurando-se como uma pesquisa participante para a qual se utilizou de questionário aplicado a 50 clientes da loja, no momento em que consumiam produtos e serviços; entrevista com o proprietário e observação e vivência no ambiente de varejo. Identificou-se que existem grupos de profissionais motivados pela ideia de sair do ambiente institucional para frequentar locais de varejo alternativos, cujo formato permite a interlocução de assuntos referentes a trabalho, pesquisa dentre outros.

É possível constatar nesse modelo, peculiaridades desse tipo de negócio, que ainda inovador, poderá aprimorar seu formato. Constatou-se que pessoas e grupos, buscam esses espaços não apenas para negócios propriamente ditos, mas, para leituras, estudos e pesquisas.

O comportamento do consumidor é multifuncional e esses locais são propícios, pois instigam, despertam sensações, inspiram e trazem à tona o prazer aliado ao trabalho.

\section{Surgimento do Coworking: aliando teoria e realidade}

O tema coworking ainda é pouco explorado, por se caracterizar como uma inovação tanto como empreendimento, como forma de trabalho. Ambientes inovadores já são realidade em muitas cidades brasileiras, como é o caso do coworking spaces. Salles Filho, Bonacelli e Mello (1999) ressaltam que os ambientes de inovação estimulam a relação universidade, empresas, governo e sociedade, criando uma nova dinâmica de aprendizados, convergindo para a efetivação do conceito de Tríplice Hélice.

O termo coworking foi mencionado pela primeira vez em 1999 por Bernie DeKoven ao descrever o trabalho colaborativo realizado com o apoio de computadores e novas tecnologias (LEFORESTIER, 2009). A partir de 2005, passou a ser difundida a ideia de coworking spaces, que envolve o espaço físico onde trabalhadores independentes e itinerantes se reúnem para trabalhar em um espaço informal.

Com rotinas de trabalho cada vez mais colaborativas, a tendência é que esse modelo se torne mais viável a cada ano, uma vez que cria uma comunidade empreendedora, onde todos podem contribuir para o crescimento dos outros e compartilhar ideias, experiências, negócios e ampliação da rede de contatos.

O coworking spaces tem como propósito o compartilhamento de estrutura física, mobiliário, custos de locação, serviços de telefonia, internet e secretária, bem como, de um endereço comercial, gerando um ambiente propício ao networking, a troca de experiências, o compartilhamento de conhecimentos, a participação de eventos e a programas de capacitação (FOST, 2008; LEFORESTIER, 2009).

Através do coworking procura-se resolver basicamente quatro tipos de problemas: empreendedores que desejam evitar gastos de um escritório próprio; pessoas que querem aumentar seu networking com profissionais de sua área ou outras diferentes; pessoas que buscam maior interação com outros profissionais no seu ambiente de trabalho e; profissionais ou empreendedores que fazem uso de home-office, porém sentem-se isolados nessa modalidade de trabalho (ANDRICH, 2017). 
O objetivo e diferencial do coworking é que além de oferecer um espaço, traz um ambiente favorável ao relacionamento, troca de experiências e networking. Acontece a qualquer momento quando mais de uma pessoa motivada se reúne com a intenção de trabalhar e criar valor compartilhado em benefício da comunidade (KWIATKOWSKI; BUCZYNSK, 2011).

Quando se trabalha em casa, por exemplo, a pessoa acaba com o passar do tempo, perdendo suas habilidades sociais, seu equilíbrio, suas conexões. Ela percebe que está perdendo "sua tribo", aquela que tinha na faculdade ou quando trabalhava fora de casa. E, o Coworking, traz, na concepção de Kwiatkowski e Bruczynsk (2011) os preenchimentos que se precisava, pois trata-se de:

um fenômeno que acontece em espaços de trabalho compartilhados e colaborativos nos quais a ênfase está na comunidade (não no espaço), nas relações e na produtividade. Coworking tem o seu fundamento no domínio freelance / self-employed, mas expandiu-se para incluir pequenas e médias empresas, sem fins lucrativos, funcionários remotos e emergentes. Coworking é um estado de espírito, uma comunidade, e o mais importante, um revolucionário elemento de maior movimento colaborativo de consumo (p. 6).

A pesquisa revela esse perfil multifuncional, tanto do novo varejo quanto do novo consumidor, que busca unir em um mesmo ambiente, cultura, entretenimento, formas de compartilhar experiências e trabalho. Existem grupos de profissionais motivados pela ideia de sair do ambiente institucional para frequentar locais de varejo alternativos, cujo formato permite a interlocução de assuntos referentes a trabalho, pesquisa, etc. Entre esses locais, pode-se utilizar o caso da Literatus Xok's, franquia, cujo gestor ao iniciar o empreendimento não tinha essa proposta, mas que foi acontecendo naturalmente assumida por grupos de consumidores, como se percebe:

(...) eu penso que os públicos transformam os espaços que ocupam a partir de seus desejos e das suas necessidades. Assim como alguns podem ter pensado em um ambiente de lazer, nós transformamos esse espaço em duas coisas: trabalho e o lazer (João, professor universitário).

O negócio da empresa constitui-se em uma Livraria, Cafeteria, Chocolateria e Sorveteria, conjugados em um mesmo ambiente. O café e os livros, historicamente possuem uma relação fazendo parte da lenda dos primeiros cafés vienenses, onde "muitos cafés passaram a oferecer seu espaço para seções literárias, nas quais jovens escritores e poetas poderiam apresentar-se" (BUENO, 2011), p. 30), fazendo-se então, do café um ponto de leitura. Desse modo, a Literatus Xok's reunindo esses produtos, possibilita que o próprio público, vá descobrindo novas sensações e novas utilidades para o ambiente de sua loja, compartilhando companhia e conhecimento.

Na concepção de Gandini (2015) espaços de coworking se caracterizam como locais de trabalho utilizados por profissionais de diversas áreas, em sua maior parte freelancers, onde as variadas formas de conhecimento são compartilhadas. Foi desenvolvido basicamente em instalações onde os trabalhadores compartilhavam uma secretária e uma conexão wi-fi.

Campos, Teixeira, Schmitz (2015) citam novos modelos de ambientes de inovação criados por Jackson (2013), que os categoriza em: a) labs, b) university labs, c) incubadoras, d) home office, e) coworking space e f) coffee shops. Para a pesquisa, utiliza-se como modelo este último, que são as cafeterias que percebem o potencial de um espaço diferente do habitual e são 
percebidos assim também pelos clientes.

Outro modelo de coworking já estudado por Ramuski e Carlomagno (2017) é o Coworking space - CWS, que não representam um formato de varejo, mas sim um modelo para organizações, comunidades e profissionais liberais trabalharem, por meio do compartilhamento de um mesmo espaço, visando uma redução dos custos fixos.

Leforestier (2009) em seus estudos analisa através da ferramenta estratégica SWOT (Strengths, Opportunities, Weaknesses e Threats - Forças, Oportunidades, Fraquezas e Ameaças) o modelo organizacional de uma empresa de coworking, conforme quadro 1.

Quadro 1: Análise SWOT do modelo organizacional Coworking

\begin{tabular}{|c|c|}
\hline PONTOS FORTES & PONTOS FRACOS \\
\hline Economia em relação ao escritório convencional & Pouca privacidade \\
\hline Custo flexível & Propriedade intelectual vulnerável \\
\hline Grande diversidade de serviços & Projetos expostos \\
\hline Socialização & Motivação reduzida por não ser exclusivo \\
\hline Interação e colaboração benéfica & Dificuldades na adequação/compatilhamento do espaço \\
\hline Possibilidade de participar de eventos & Falta de comparecimento \\
\hline \multicolumn{2}{|l|}{ Participação em uma comunidade } \\
\hline \multicolumn{2}{|l|}{ Ambiente inovador } \\
\hline \multicolumn{2}{|l|}{ Colaboradores talentosos de diferentes áreas } \\
\hline OPORTUNIDADES & AMEAÇAS \\
\hline Ampliação dos serviços ofertados & Problemas com segurança (confidencialidade de idéias) \\
\hline Coworking dedicado a setores especificos & Concorrência com "cafés" que oferecem espaço \\
\hline Conceito com expansão em nivel mundial & Flexibilidade com o desenvolvimento da tecnologia $3 \mathrm{G}$ \\
\hline Criação de comunidade para expansão de idéias & Baixa de investimento com crises econômicas \\
\hline Modelo pode ser inserido nas empresas & \\
\hline
\end{tabular}

Fonte: Adaptado de Leforestier (2009).

Assim como proposto por Leforestier (2009) adaptando a teoria à prática, desenvolveu-se o modelo organizacional da empresa Literatus Xok's, cujas variáveis em alguns momentos, possuem pontos em comum aos espaços de coworking (quadro 2). 
Quadro 2: Análise SWOT do modelo organizacional da Literatus Xok's

\begin{tabular}{|c|c|}
\hline Pontos Fortes & Pontos Fracos \\
\hline $\begin{array}{l}\text { Oferta diversificada (livros, cafés, chocolates, } \\
\text { sorvetes). } \\
\text { Ambiente atrativo e sensorial. } \\
\text { Qualidade na Produção dos Produtos "obras de } \\
\text { arte". } \\
\text { Excelência no serviço de Atendimento. Permite socia- } \\
\text { lização. } \\
\text { Oferta de produtos atendendo diferentes estações do } \\
\text { ano. } \\
\text { Experiência de socialização perfeita para evitar o } \\
\text { trabalho solitário e improdutivo } \\
\text { em casa. }\end{array}$ & $\begin{array}{l}\text { Pouca privacidade. } \\
\text { Mesas pequenas para o uso dos grupos de trabalho. } \\
\text { Demora na entrega dos pedidos. } \\
\text { Falta de lugares em dias de grande fluxo de clientes. } \\
\text { Poluição sonora em dias de muito fluxo. }\end{array}$ \\
\hline Oportunidades & Ameaças \\
\hline $\begin{array}{l}\text { Conceito em expansão para esse tipo de negócio. } \\
\text { Aumento da criação de grupos } \\
\text { de compartilhamento de ideias. } \\
\text { Carência no município. }\end{array}$ & $\begin{array}{l}\text { Concorrência de "Cafés" e "Sorveterias". Crise eco- } \\
\text { nômica. }\end{array}$ \\
\hline
\end{tabular}

Fonte: elaborado pelas autoras (2016).

Na Loja de Varejo Literatus Xok's os serviços prestados não se caracterizam exatamente como um ambiente de coworking, mas como um novo formato de varejo que vem sendo utilizado para outros fins que não seja apenas o lazer e o entretenimento, mas sim, atividades que envolvem grupos formais que se reúnem para dialogar, pesquisar e compartilhar ideias. Afinal, o coworking vai além da infraestrutura, da comodidade e do custo (geralmente mais baixo do que manter um escritório próprio), outras grandes forças impulsionam esses lugares como o ambiente ideal para multiplicar ideias, contatos e novos negócios: os eventos formais e informais (que estimulam a troca de aprendizado em sessões de mentorias) e o espírito de colaboração entre os residentes (FEIJÓ, 2017).

Existem hoje, grupos informais frequentadores nesse intuito na Literatus Xok's. Um deles possui a denominação de "Com café" (Figura 1), criado pela demanda por inovação e criatividade nas ações dos professores; o corpo docente dos cursos de Comunicação da Unijuí (Universidade Regional do Noroeste do Estado do Rio Grande do Sul) definiu a realização e um encontro mensal para a discussão de temáticas atuais, num espaço fora da universidade. 


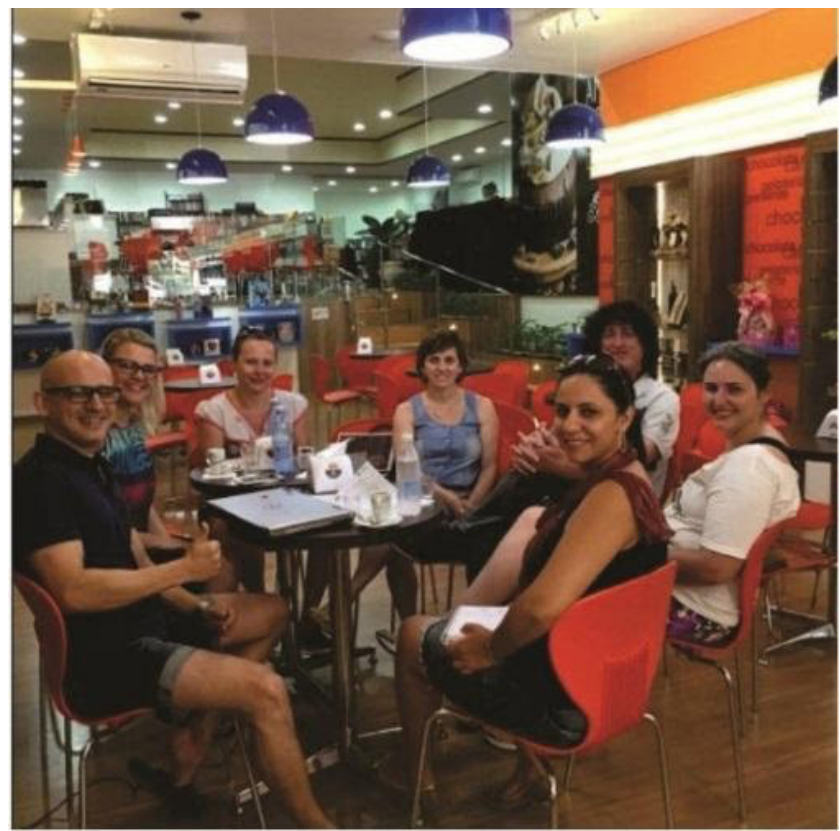

Figura 1: Grupo Informal "Com Café"

Fonte: arquivo pessoal das autoras

Para que os objetivos traçados pelo grupo fossem atingidos com excelência, o local escolhido para os encontros deveria ter características que estimulassem as sensações positivas e fomentassem as discussões sobre a criatividade e inovação e, além disso, apresentasse infraestrutura, atendimento e um excelente café. Sobre as reuniões inicialmente tinha-se a ideia de serem feitas cada vez em um local distinto, entretanto, mencionam que "está ficando tão interessante aqui, que encontramos dificuldades em ir a outro local." (Maria, participante entrevistada). O primeiro "Com Café" foi realizado na manhã do dia 25 de fevereiro de 2016. Um momento para refletir sobre a prática docente ocupando lugares para além da universidade.

Outro grupo informal frequentador do local, recebeu a denominação de "Pense Marketing" (figura 2), formado por três professoras e pesquisadoras universitárias de três instituições distintas. Inicialmente iniciou como um encontro entre as integrantes, despertando a vontade de se trabalhar também naquele local, uma vez que, o ambiente agradável, propicia novas ideias, novas formas de pensar temáticas contemporâneas do marketing - foco das pesquisas por elas realizadas. Os encontros acontecem de acordo com as demandas de trabalho, em uma média de uma vez ao mês.

Cabe mencionar, que os encontros realizados por ambos os grupos são divulgados por seus membros nas redes sociais, o que estimula o interesse de novos pesquisadores a se agregarem ao grupo, além da divulgação da loja de varejo Xok's, como uma nova proposta diferenciada. 


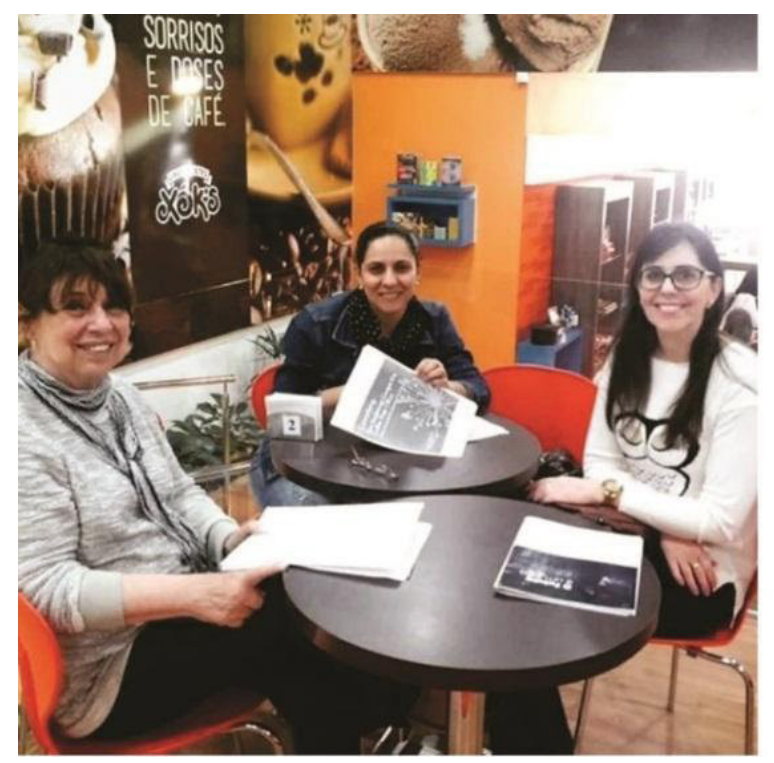

Figura 2: Grupo Informal "Pense Marketing"

Fonte: arquivo pessoal das autoras.

$\mathrm{Na}$ existência desses dois grupos informais percebe-se exatamente o que Kwiatkowski e Bruczynsk (2011) descrevem como sendo o coworking: um novo fio que liga profissionais independentes juntos, que não possui algo relacionado a cargo e, sim, sobre as comunidades às quais você pertence. "Não é apenas sobre ter uma mesa ou trocar cartões de visita com seus colegas de trabalho. Nunca foi assim. Trata-se de fazer parte de um movimento que está mudando a face do trabalho como a conhecemos" (p. 6).

É possível constatar nesse modelo, peculiaridades desse tipo de negócio, que ainda inovador, poderá aprimorar seu formato. Mais comuns em grandes centros, começam a ser opção de negócio também em pequenas cidades, cujo hábito de frequentar esses locais começa a ser formado.

Para Brown (2017), os CWS estão sendo percebidos como um novo "Third place" para se trabalhar, uma vez que escritórios dentro de empresas seriam "os primeiros", home-offices seriam "os segundos" e locais públicos como livrarias, cafés e bibliotecas são os atuais "terceiros espaços" - que reúnem profissionais independentes, micro negócios e startup, sendo uma solução para espaços profissionais de trabalho, principalmente para jovens empreendedores.

No caso de Ijuí - município da Região Noroeste do Estado do RS - onde está instalada a Literatus Xok's, não existia até então, um formato de varejo que agregasse cafeteria, chocolateria, livraria e sorveteria em um mesmo local. Mesmo caracterizada como uma cidade do interior do Estado, aos poucos grupos de pessoas começam a despertar seu interesse pelo local não apenas para o consumo em si, mas para trabalhar, estudar, conversar. A palavra consumo, aliás, assume concepções diferentes.

A ambiguidade da definição do termo consumo está imbricada das formas que as pessoas se apropriam do universo à sua volta (BARBOSA; CAMPBELL 2006). O consumo dos objetos desejados ou por necessidade constituem grupos que realizam troca de informações e que transformam as relações entre os indivíduos. A transformação dessas relações pode desencadear novas formas de consumo ou reflexões acerca da sociedade e seus comportamentos dian- 
te ao entorno midiático. O consumo entendido além de somente os "sujeitos que usam objetos" fomenta a lógica de que todo consumo é cultural (SLATER, 2002 p. 104). "A função essencial do consumo é a sua capacidade de dar sentido" (DOUGLAS; ISHERWOOD, 2004, p. 108).

As cidades vivem e se desenvolvem através do consumo. Entrevistas realizadas demonstram a satisfação dos clientes, quando mencionam que "a cidade merecia um local assim" (Claudia, estudante), já que até então, não existe concorrência similar.

Para Moriset (2013), a abundância de coworking spaces em uma determinada cidade tem algo a ver com o tipo de vivacidade urbana e vibração que faz com a cidade seja um cenário para criativos, empreendedores e organizações baseados em conhecimentos, independentemente da presença de um ecossistema de alta tecnologia. O contexto sociocultural de uma cidade reflete os valores, costumes e tradições da sociedade, inclui seus hábitos de vida, valores sociais, atividades e hábitos de seus cidadãos que possuem novos modos de comportamento e, consequentemente, novas exigências e novos modelos de negócios, como é o caso dos coworking spaces.

\section{A casa, a rua o trabalho e os novos espaços de varejo multifuncionais}

DaMatta (1986) divide a vida social brasileira em três espaços essenciais: o universo da casa, do lar e do trabalho. E, observa-se nas cidades brasileiras um nítido movimento: do trabalho para casa, de casa para o trabalho. A 'casa' e a 'rua' são categorias sociológicas para os brasileiros, estas palavras não designam simplesmente espaços geográficos ou coisas físicas comensuráveis, mas acima de tudo entidades morais, domínios culturais institucionalizados e, por causa disso, capazes de despertar emoções, reações, leis, orações, músicas e imagens esteticamente emolduradas e inspiradas.

A casa é caracterizada pelo autor como um lugar de calma, tranquilidade e morada composta por membros de uma família e de um grupo fechado com limites bem-definidos. Já a rua é um lugar de movimento, luta, competição, individualidade, mas também de lazer. Além de tudo, "a rua é o espaço que permite a mediação pelo trabalho - o famoso "batente", nome já indicativo de um obstáculo que temos que cruzar, ultrapassar ou tropeçar. Trabalho no nosso sistema é concebido como castigo" (DAMATTA, 1986, p. 5).

Mesmo, cada espaço tendo suas características, existe uma linha tênue entre eles. Hoje tais limites, tornam-se invisíveis, uma vez que, leva-se trabalho para casa, a rua é lugar de trabalho e as relações de casa permeiam a rua e o trabalho. As relações e os espaços não possuem mais fronteiras, as pessoas clamam por qualidade de vida, trabalhar naquilo que gostam, fazer das cidades lugares de bem viver. Surge nessa perspectiva, a difusão da casa, da rua e do trabalho, emergindo espaços multifuncionais.

Nesse contexto contemporâneo, muitas organizações estão investindo em diferenciadas experiências em seus pontos de venda, com o objetivo de atrair mais clientes. "Na verdade, as empresas encenam uma sensação sempre que envolvem os clientes, conectando-se a eles de forma pessoal, memorável" (PINE; GILMORE, 1999, p. 140).

Atualmente o varejo é considerado um dos maiores setores da economia global (BERKOWITZ et al, 2003; LEVY; WEITZ, 2000; MORGADO; GONÇALVES, 1999). Para 
Zamberlan e Sparemberg (2009, p. 13), sua importância está atrelada à "capacidade em incorporar e adotar avançadas tecnologias de informação e de gestão, respondendo com rapidez às transformações e modificações do ambiente, principalmente aquelas relacionadas com mudanças no comportamento do consumidor". Por isso hoje, o setor recebe destaque como um dos principais responsáveis pelo crescimento do país em termos econômicos, sociais e ambientais.

As lojas estão se transformando em grandes eventos temáticos. Solomon (2011) aborda a estratégia temática popular de converter uma loja em um espaço de estar - a ideia de casa mencionada por DaMatta (1986). Ao investir em um ambiente que proporcione sensações positivas aos clientes, as lojas podem ter mais possibilidades de compras repetidas e fidelização. Existe grande relevância nesse contexto, dos sentidos (sabor, som, cheiro, tato e visão), uma vez que podem tornar o consumo prazeroso, não apenas "por seus estímulos sedutores, como também, por evocar imagens mentais geradas por esses estímulos, baseadas na lembrança de experiência anteriores" (COBRA; BREZZO, 2010).

No estudo com clientes da Literatus Xok's identificaram-se atributos valorizados e que os fazem vivenciar uma experiência diferenciada no ambiente de loja. Dos pesquisados, 59,2\% (Quadro 3) apontam o ambiente como um lugar aconchegante que traz familiaridade, caracterizando-o como um espaço para momentos em família. Isso também aparece na fala do gestor quando ele comenta que clientes mencionam o fato de poder deixar os filhos frequentarem o local com tranquilidade.

Quadro 3: Atributos percebidos pelos clientes da Literatus Xok's

\begin{tabular}{|c|c|c|}
\hline \multicolumn{3}{|c|}{ QUADRO DE ATRIBUTOS PERCEBIDOS PELOS CLIENTES } \\
\hline & Atributos & $\begin{array}{c}\% \text { dos entrevistados que } \\
\text { concordam }\end{array}$ \\
\hline 1 & Um lugar de aconchego e familiaridade. & $100 \%$ \\
\hline 2 & Qualidade no atendimento. & $91,5 \%$ \\
\hline 3 & O ambiente é adequado para uma reunião informal. & $89.8 \%$ \\
\hline 4 & É um lugar de momentos com a família. & $95,9 \%$ \\
\hline 5 & É um espaço para bate papo com os amigos. & $93,8 \%$ \\
\hline 6 & Ambiente proporciona uma experiência única. & $64,6 \%$ \\
\hline 7 & Ambiente completo. & $61,7 \%$ \\
\hline 8 & A iluminação local é adequada para leitura e trabalho. & $63,8 \%$ \\
\hline 9 & A localização é um dos pontos importantes. & $93,9 \%$ \\
\hline 10 & A cidade precisava de um local assim. & $100 \%$ \\
\hline 11 & As cores e imagens dos produtos aguçam o meu desejo de consumir. & $87,8 \%$ \\
\hline 12 & Lugar para lazer e atividades profissionais. & $46,8 \%$ \\
\hline 13 & A estrutura física, como mesas e cadeiras, é apropriada. & $83,7 \%$ \\
\hline 14 & É um espaço que estimula as sensações, me sinto seduzido (a). & $77,1 \%$ \\
\hline 15 & A música é adequada à proposta do ambiente. & $77,8 \%$ \\
\hline
\end{tabular}

Fonte: pesquisa de campo.

Destacar-se frente à concorrência é uma estratégia de sobrevivência, e, por isso, a economia de atenção no ponto-de-venda, por meio de iluminação cenográfica, decoração temática, criatividade na disposição dos produtos, degustação, fachadas interessantes, aroma e som constituem técnicas que precisam ser exploradas pelo varejo (BLESSA, 2005). 
A música é indispensável no ambiente da loja, pois pode promover um envolvimento maior dos clientes. Assim como a cor e a iluminação, a música pode acrescentar ou depreciar atmosfera geral da loja (BLESSA, 2005). Uma das regras de convivência em ambientes colaborativos é que haja respeito ao espaço individual, sendo assim, a música deverá ser concebida como background discreto, visando tornar o ambiente agradável a diversidade de negócios e reuniões realizadas no local.

As cores podem até mesmo influenciar as emoções do consumidor de maneira mais direta. As evidências sugerem que algumas cores (particularmente, o vermelho) criam um sentimento de excitação e estimulam o apetite; já outras cores (como o azul), criam sentimentos mais relaxantes (SOLOMON, 2011). Na empresa em estudo nota-se o investimento em construir um ambiente diferenciado com cores e imagens que aguçam o desejo de consumir do cliente, como aponta o resultado do Quadro 3.

O ambiente de uma loja, por meio das cores, pode estimular sensações que resultem na empatia com produtos, marcas e a possibilidade de venda. Os objetivos primordiais das combinações de cores visam atrair consumidores e ainda o destaque de algumas mercadorias.

Na projeção de um ambiente de loja, é muito importante que se tenha clareza do posicionamento deste negócio para o cliente. Todo o ambiente comunica, e o cliente decodifica os códigos. As cores, o mobiliário, o cheiro, a organização e limpeza, todos esses elementos e outros tantos vão estabelecendo marcas e características do negócio para os consumidores.

Mesmo sem o parecer científico, é possível reiterar que a iluminação muda o humor e o comportamento dos consumidores. Um plano de iluminação pode sugerir classe, privacidade, atendimento personalizado ou, ao contrário, pode sugerir autosserviço, praticidade ou descontração (BLESSA, 2005, p. 35).

Além de toda competitividade existente, as empresas contemporâneas, se veem frente a um novo perfil de consumidor. Além de entreter, elas devem envolvê-lo de forma pessoal, provocando o que Pine II e Gilmore (1999), denominam de sensações. Enquanto as commodities são consideradas fungíveis, os bens, tangíveis, e os serviços intangíveis, as sensações são memoráveis. São essas sensações que agregam maior valor e garantem uma experiência diferenciada ao consumidor. "A empresa encenadora de sensações - não apenas fornece bens ou serviços isolados, mas também a emoção resultante, cheia de sensações que causam no cliente" (PINE II; GILMORE, 1999, p. 49).

Encontra-se respaldo em Cobra e Brezzo (2010) ao afirmarem que os indivíduos consomem produtos em busca do prazer e não apenas por necessidades funcionais, assim se está migrando do foco no produto para o foco na experiência, as quais despertam tais sensações. $\mathrm{O}$ consumo de experiência representa uma das mais expressivas manifestações da sociedade atual.

Nesse aspecto, é interessante frisar a fala de uma das consumidoras quando ela se refere ao fato de frequentar a Literatus Xok's: "vir aqui é se dar um presente" (Roberto, funcionária pública), ou seja, a experiência por ela vivida traz essa sensação de estar sendo presenteada. 


\section{Conclusões}

Uma sociedade de compartilhamento é uma realidade atual, envolvendo redes de informações, ideias, ações. O consumidor demonstra interesse por empresas que possibilitem novas vivências no ato de consumir, seja um produto ou um serviço. Diante dessa realidade, o varejo vem ganhando novas configurações visando atender as demandas de um consumidor multifuncional. Novos espaços e formatos de loja permitem que em um mesmo lugar seja possível reunir e conciliar trabalho, estudo, lazer, o que resulta em construções informais de um assemelhado a coworking.

O mercado vem criando nichos de todos os tipos e já existem coworkings específicos para cada tipo de profissional e suas demandas. Identificados como ambientes de inovação, o presente estudo, elucida o caso da Literatus Xôck's, categorizada por Campos, Teixeira, Schmitz (2015) como Coffee Shop ou cafeterias que atendem demanda de profissionais que buscam um espaço com segurança, internet, mesas e tomadas de energia, assim como a possibilidade de relacionamento com outras pessoas.

Cabe ressaltar que esse formato de negócio varejista, presente em grandes e já despontando nas pequenas cidades, permite a inserção de novas tipologias e multifuncionalidades. Quando se menciona aqui, o trabalho compartilhado, a palavra trabalho agrega várias outras dimensões. Pessoas e grupos, buscam esses espaços não apenas para negócios propriamente dito, mas, para leituras, estudos e pesquisas. O comportamento do consumidor é multifuncional e esses locais são propícios, pois instigam, despertam sensações, inspiram e trazem à tona o prazer aliado ao trabalho.

Nesses espaços propicia-se aos coworkers um ritmo de trabalho, à medida que os tira da informalidade do lar ou dos terceiros espaços. Podem também sediar projetos culturais e sociais, trazendo inspirações profissionais, onde se partilha mais que o tangível, como informação e conhecimento (BOUNCKE; REUSCHL, 2016).

O estudo ainda incipiente de lojas de varejo com outra concepção, que também vêm a acolher grupos de coworking, é importante uma vez que aporta conhecimentos para tornar os espaços possíveis de se tornar "momentos memoráveis" em um mundo que preza por experiências e sensações.

Estas constatações envolvem premissas que se visualizam, como alvissareiras num futuro próximo, e que se desvanecem, desmancham no ar, com o advento de algo tão inesperado e insuspeitado como a pandemia provocada pelo coronavírus. A realidade antevista no artigo, relacionada ao coworking voltará? Ela se configura momentaneamente como impossível. Como as pessoas seguirão trabalhando?

O Home office, realidade atual do trabalho de grande parte da massa trabalhadora, já desponta como um futuro consistente, a concorrer e também se aliar com a modalidade presencial, mesmo pós-Covid.

Diante de tantas incertezas, e a necessidade de se reinventar o negócio, o coworking deverá passar por transformações. É uma solução que faz muito sentido e agora ainda mais, porque as empresas estão vendo que o trabalho remoto é viável. 
Pesquisas recentes identificam quesitos favoráveis e desfavoráveis ao trabalho em casa. Destacam-se alguns resultados do estudo efetivado por Almeida, Ceretta e Froemming (2020).

O teletrabalho consiste em atividade profissional que é realizada fora do ambiente da empresa empregadora e auxiliado por tecnologia de transmissão de dados. Esta realidade teve que, no transcurso da pandemia, ser assumida de maneira atribulada: requeria celeridade e não teve o tempo necessário ao devido planejamento. Está se construindo ao mesmo tempo em que é exigida, o que trouxe pontos para se refletir e propor ajustes para os passos vindouros.

Na pesquisa referida (ALMEIDA; CERETTA; FROEMMING, 2020), 40\% dos entrevistados já tinha experiência na modalidade de trabalho à distância, $60 \%$ eram neófitos. Percebeu-se a falta de suporte fornecido pelas empresas que também não estavam preparadas. Apesar disso, com relação à produtividade, apenas $24 \%$ consideraram que houve queda, $40 \%$ até consideraram ter aumentado.

Embora haja reuniões e encontros on-line com chefias e colegas, ainda não apresentam uma periodicidade estabelecida e uma das lacunas apontadas são a falta de entrosamento ocorrido e a falta de contato proporcionado pelos encontros físicos.

Ainda, a considerar outros percalços apontados como a falta de infraestrutura adequada em casa: interferência das atividades laborais com as tarefas rotineiras da casa, intensificadas com o isolamento social: filhos e companheiros também com suas atividades de rua agora acontecendo em casa. Então o viver público e o privado estão entrelaçados.

Portanto, poderá surgir um novo público para os espaços de coworking, formado por aquelas empresas que nem cogitavam a ideia de não ter um escritório próprio, mas que devido aos altos custos e a crise instaurada pela Covid-19, serão obrigadas a desistir desse formato padrão. Os empresários vão refletir muito antes de entrar em contratos de longo prazo e irão procurar soluções mais flexíveis, como os espaços coworking. Outra percepção é que após a pandemia as empresas de grandes centros adotarão novas formas de trabalho e uma das tendências é o "close to home", trabalhar perto de casa para diminuir deslocamentos de seus colaboradores. Além disso, o coworking também será uma alternativa para proprietários de imóveis ociosos que precisarem rentabilizá-los, no período que virá pós pandemia.

Por toda a experiência vivenciada, a tendência é que as pessoas retornem ao trabalho ainda mais carentes por interações com colegas, clientes, enfim, necessidade de se relacionar e trocar ideias e sentimentos. Os coworkings são uma ótima opção nesse sentido, tornando-se claro, o ambiente físico seguro. Entretanto, será preciso investir em tecnologias de baixo contato, como portas e dispensers automáticos, sensores nos ambientes, além de todos os equipamentos de segurança que fazem parte dos protocolos da Organização Mundial da Saúde, distanciamento mínimo pré-determinado, uso de máscaras, painéis de separação em acrílico, entre outros.

Estas constatações induzem a refletir sobre a relação do tema central do estudo deste artigo: o coworking como a nova modalidade de teletrabalho que deve permanecer pós-Covid e terá de se reconfigurar.

Tem-se três pontos identificados que necessitam se reinventar, se reconfigurar: lojas de varejo, coworking e teletrabalho, sem usar o termo home office, pois não necessariamente será 
no home-lar das pessoas, este home pode tomar novas configurações. Quem sabe em espaços de varejo que precisam também se reinventar?

\section{REFERÊNCIAS}

ALMEIDA, Márcia; CERETTA, Simone; FROEMMING, Lurdes. Trabalhando em Home Office. Disponível em: https://www.linkedin.com/posts/marciaalmeidaexperience pensemarketing-homeoffice-trabalhoremoto-activity-6681266948233273344-ViH5 Acesso em: $29 / 06 / 2020$.

ANDRICH, Mara. Compartilhar ou não compartilhar: eis a questão. Revista Brasileira de Administração. Ed. 116. Jan/Fev de 2017.

BERKOWITZ, Eric N.; KERIN, Roger A.; HARTLEY, Steven W.; RUDELIUS, William.

Marketing. v. 2. Rio de Janeiro: LTC, 2003.

BLESSA, Regina. Merchandising no ponto-de-venda. São Paulo: Atlas, 2005.

BOUNCKE, Ricarda B., REUSCHL, Andreas J., CWS - spaces: how a phenomenon of the sharing economy builds a novel trend for workplace and for entrepreneuship. Management Science.

22 sep. 2016. Disponível em: https://link.springer.com/article/10.1007\%2Fs11846016-0215-y. Acesso em 20/04/2018.

BUENO, Ricardo. O café e o Iluminismo. In: BUENO, Ricardo. A história da economia brasileira: dos cafezais nasce um novo Brasil. Porto Alegre: Quatro Projetos, 2011.

BURKE, Peter; BRIGGS, Asa. Uma história social da mídia: de Gutenberg à internet. Rio de Janeiro: Zahar, 2006.

BROWN, Julie. Curating the "Third Place"? CWS and the matiation of creativity. Geoforum, n. 82, p. 112-126. 11 abr. 2017. Disponível em: https://www.sciencedirect.com/science/article/pii/ S0016718517300866?via\%3Dihub. Acesso em: 12/04/2018.

CAMPOS, J. G. C.; TEIXEIRA, C. S.; SCHMIT, A. (2013). Coworking Spaces: Concepts,

Types and Features. Disponível em: <https://www.researchgate.net/publication/282701860 Coworking Spaces Concepts Types and Features>. Acesso em: 14/07/2017.

COBRA, Marcos; BREZZO, Roberto. O novo marketing. São Paulo: Elsevier, 2010. DaMATTA, Roberto. O que faz o Brasil. Rio de Janeiro: Editora Rocco, 1986.

FEIJÓ, Bruno Vieira. O mapa do coworking no Brasil. Pequenas empresas grande negócios. $\mathrm{n}^{\mathrm{o}}$ 342. Julho, 2017. 
FOST, D. (2008). Coworking: a cooperative for the modern age. The New York Times, São Francisco, 21 de fevereiro de 2008.

GANDINI, A. The rise of coworking spaces: A literature review. Ephemera, v. 15, n. 1, p. 193-205, 2015.

KWIATKOWSKI, Angel; BUCZYNSKI, Beth. Coworking: How freelancers escape the coffee shop office, 2011

LEFORESTIER, A. (2009). The coworking space concept. CINE Term Project. Indian Institute of Management (IIMAHD). Ahmedabad.

MORGADO, Maurício Gerbaudo; GONÇALVES, Marcelo Neves. Varejo: administração de empresas comerciais. São Paulo: Editora SENAC, 1999.

MORISET, B. (2013). Building new places of the creative economy. The rise of coworking spaces. Recuperado em 26 de agosto de 2015 em https://hal-univ lyon3.archivesouvertes. fr/ halshs-00914075/document.

PARENTE, Juracy. Varejo no Brasil: gestão estratégica. São Paulo: Atlas, 2000.

PINE II, Joseph; GILMORE, James. O espetáculo dos negócios: desperte emoções que seduzam os clientes, sensações intensas determinam o valor de produtos e serviços. Rio de Janeiro: campus, 1999.

RAMUSKI, Carmen Lidia; CARLOMAGNO Isabella Cappucci . Coworking no Varejo: um estudo de caso no comércio alimentício. CLAV - $11^{\circ}$ Congresso Latino-Americano de Varejo 2017. Out., São Paulo, 2017. Disponível em: http://bibliotecadigital.fgv.br/ocs/index.php/clav/ clav2017/paper/viewPaper/6136. Acesso em: 29/05/2018.

SALLES FILHO, S. L. M.; MELLO, D L.; BONACELLI, M. B. M. (1999). Reorganização

institucional como um processo de modernização das relações entre os agentes de inovação. In: Gomes, M. F. M., \& Costa, F. A. (orgs.). (Des) Equilíbrio Econômico e Agronegócio. Viçosa.

SEBRAE. Co-working é uma boa prática para os pequenos negócios. 2015. Disponível em:

http://www.sebrae.com.br/sites/PortalSebrae/artigos/co-working-e-uma-boa-pratica-para-os-p equenos negócios. Acesso em: 28 mai. 2016.

SOLOMON, Michael R. O comportamento do consumidor: comprando, possuindo e sendo. Porto Alegre : Bookman, 2011.

VERGARA, Sylvia C. Projetos e relatórios de pesquisa em administração. São Paulo: Atlas, 2010. 
ZAMBERLAN, Luciano; SPAREMBERG, Ariosto (Org.). Gestão de varejo: estratégias e comportamento do consumidor. Ijuí: Unijuí, 2009. 